Available online at GSC Online Press Directory

GSC Biological and Pharmaceutical Sciences

e-ISSN: 2581-3250, CODEN (USA): GBPSC2

Journal homepage: https://www.gsconlinepress.com/journals/gscbps

(RESEARCH ARTICLE)

\title{
Novel stability indicating RP-HPLC method for the simultaneous estimation of tobramycin and loteprednol in pharmaceutical dosage forms
}

\author{
Nagaraju Pappula *, Kiran Kumar Palaparthi, Aparna Govindu and Suneetha M \\ Department of Pharmaceutical Analysis, Hindu College of Pharmacy, Amaravathi Road, Guntur - 522002, Andhra \\ Pradesh, India.
}

Publication history: Received on 29 November 2019; revised on 21 January 2020; accepted on 23 January 2020

Article DOI: https://doi.org/10.30574/gscbps.2020.10.1.0226

\begin{abstract}
A simple, accurate, rapid and precise isocratic stability indicating reversed-phase high-performance liquid chromatographic method has been developed and validated for simultaneous determination of Tobramycin and Loteprednol in combined tablet dosage form. The chromatographic separation was carried out on Zodiac C18 (150 $\mathrm{x}$ $4.6 \mathrm{~mm}, 5 \mu)$ with a mixture of Phosphate buffer: acetonitrile $(60: 40 \% \mathrm{v} / \mathrm{v})$ as a mobile phase at a flow rate of $1.0 \mathrm{~mL} / \mathrm{min}$. UV detection was performed at $243 \mathrm{~nm}$. The retention times were 2.442 and 3.269 min for Tobramycin and Loteprednol respectively. Calibration plots were linear (r2=0.999) over the concentration range of 3.75-22.5 $\mu \mathrm{g} / \mathrm{mL}$ for Tobramycin $6.25-37.5 \mu \mathrm{g} / \mathrm{mL}$ for Loteprednol. The method was validated for accuracy, precision, specificity, linearity, robustness, LOD and LOQ. The proposed method was successfully used for quantitative analysis of tablets. No interference from any component of pharmaceutical dosage form was observed. Validation studies revealed that developed method is specific, rapid, reliable, and reproducible. The high recovery and low relative standard deviation confirm the suitability of the method for routine determination of Tobramycin and Loteprednol in bulk and tablet dosage form.
\end{abstract}

Keywords: Tobramycin; Loteprednol; RP-HPLC; Tablets

\section{Introduction}

Tobramycin (TOBR) [1-3] (Fig-1) is an amino-glycoside, broad-spectrum antibiotic produced by Streptomyces tenebrarius. Tobramycin can be used in topical or systemic treatment. It is effective against gram-negative bacteria, especially the pseudomonas species. It is a $10 \%$ component of the antibiotic complex, produced by the same species. It is chemically $(2 \mathrm{~S}, 3 \mathrm{R}, 4 \mathrm{~S}, 5 \mathrm{~S}, 6 \mathrm{R})-4$-amino-2- $\{[(1 \mathrm{~S}, 2 \mathrm{~S}, 3 \mathrm{R}, 4 \mathrm{~S}, 6 \mathrm{R})-4,6$-diamino3 $\{[(2 \mathrm{R}, 3 \mathrm{R}, 5 \mathrm{~S}, 6 \mathrm{R})-3$-amino-6-(aminomethyl)5-hydroxyoxan-2-yl]oxy\}-2-hydroxycyclohexyl]oxy\}-6-(hydroxymethyl)oxane-3,5-diol. Loteprednol (LOTE) (Fig-2) (as Loteprednoletabonate) is a topical corticoid anti-inflammatory. It is used in ophthalmic solution for the treatment of steroid responsive inflammatory conditions of the eye such as allergic conjunctivitis, uveitis, acne rosacea, superficial punctate keratitis, herpes zoster keratitis, iritis, cyclitis and selected infective conjunctivitis. As a nasal spray, is used for the treatment and management of seasonal allergic rhinitis. Loteprednoletabonate is synthesized through structural modifications of prednisolone related compounds so that it will undergo a predictable transformation to an inactive metabolite. It is chemically Chloromethyl (1S,2R,10S,11S,14R,15S,17S)-14,17-dihydroxy-2,15-dimethyl-5oxotetracyclo[8.7.0.02,7.011,15] heptadeca-3,6-diene-14-carboxylate.

\footnotetext{
${ }^{*}$ Corresponding author

E-mail address: pappulanagaraju@gmail.com
} 


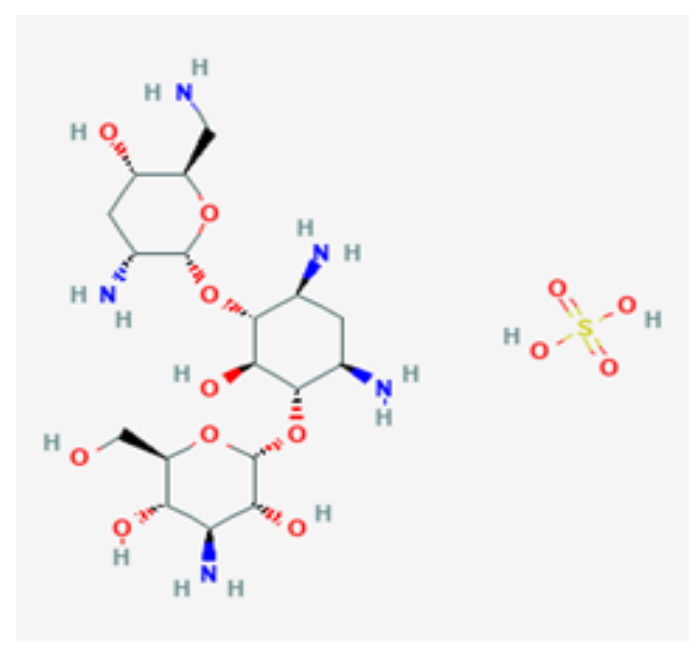

Figure 1 Molecular structure of Tobramycin

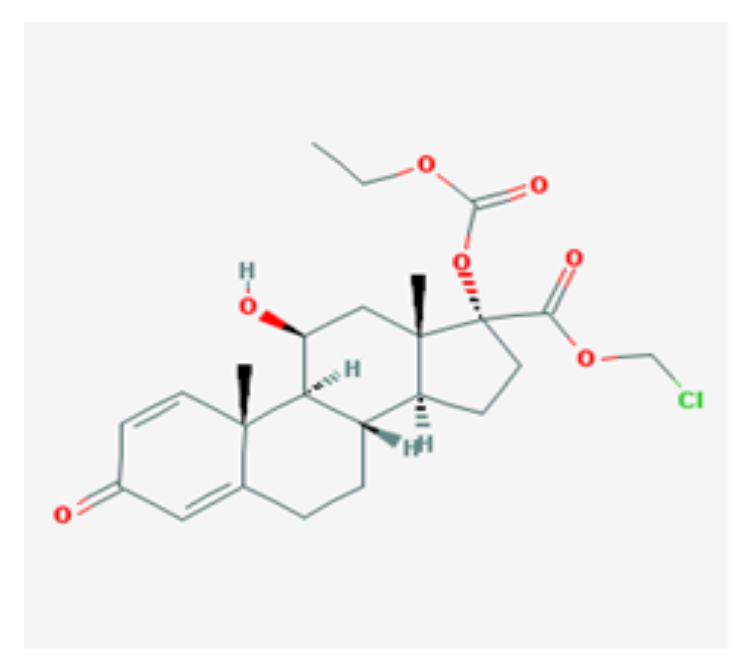

Figure 2 Molecular structure of Loteprednol

Literature survey [4-12] reveals that few Spectrophotometric and chromatographic methods were reported for estimation of TOBR and LOTE in single and combination with other drugs. In this study, an attempt has been made to develop an accurate, rapid and reproducible reverse phase HPLC method for simultaneous determination of TOBR and LOTE in combined tablet dosage form and validate it, in accordance with International Conference on Harmonization (ICH) guidelines.

\section{Material and methods}

\subsection{Chemicals and reagents}

The reference samples of TOBR and LOTE (API) were obtained from Pulse Pharmaceuticals, Hyderabad. The branded formulations LACNE gel was procured from the local market. Gel claimed to contain $0.3 \%$ TOBR and 0.5\% LOTE have been utilized in the present work. All chemicals and reagents used were HPLC grade and purchased from Merck chemicals, India.

\subsection{Chromatographic conditions}

Separation was performed on an isocratic waters HPLC 2695 system instrument equipped with a with binary pump and variable wavelength PDA detector with auto injector. Data was analysed by using Empower2 software. Degassing of the mobile phase was done by using bath sonicator. A Shimadzu balance was used for weighing the materials. The separation was achieved on a Zodiac $\mathrm{C}_{18}(150 \times 4.6 \mathrm{~mm}, 5 \mu)$ analytical column. The mobile phase consisted of phosphate buffer: acetonitrile $(60: 40 \% \mathrm{v} / \mathrm{v})$. The flow rate was $1.0 \mathrm{~mL} / \mathrm{min}$ and $\mathrm{UV}$ detection was performed at $243 \mathrm{~nm}$. The mobile 
phase was shaken on an ultrasonic bath for $30 \mathrm{~min}$. The resulting transparent mobile phase was filtered through a 0.45 $\mu$ membrane filter (Millipore, Ireland). The injection volume was $10 \mu \mathrm{L}$ and all the experiments were performed at ambient temperature.

\subsection{Preparation of Standard stock solutions}

Accurately weighed $3.75 \mathrm{mg}$ of TOBR and $6.25 \mathrm{mg}$ of LOTE standard drugs was transferred $25 \mathrm{ml}$ clean and dry volumetric flask containing $3 / 4^{\text {th }}$ volume of diluent and sonicated for 10 minutes. Flask was made up with diluent and labeled as Standard stock solution. (150 $\mathrm{\mu g} / \mathrm{ml}$ of TOBR and $250 \mu \mathrm{g} / \mathrm{ml}$ of LOTE).

\subsection{Preparation of Sample stock solutions}

20 tablets were weighed and the average weight of each tablet was calculated, then the weight equivalent to 1 tablet was transferred into a $100 \mathrm{ml}$ volumetric flask, $50 \mathrm{ml}$ of diluents was added and sonicated for $25 \mathrm{~min}$, further the volume was made up with diluent and filtered by HPLC filters $(150 \mu \mathrm{g} / \mathrm{ml}$ of TOBR and $250 \mu \mathrm{g} / \mathrm{ml}$ of LOTE).

\subsection{Method validation}

The developed method was validated according to ICH guidelines. The system suitability was evaluated by six replicate analysis of TOBR and LOTE mixture at concentrations of $1000 \mu \mathrm{g} / \mathrm{mL}$ and $100 \mu \mathrm{g} / \mathrm{mL}$. The acceptance criteria are number of theoretical plates $(\mathrm{N})$ at least 2000 per each peak and tailing factor is not more than 2.0 .

\subsubsection{Linearity}

Standard calibration curves were plotted against the concentration ranging from 3.75-22.5 $\mu \mathrm{g} / \mathrm{mL}$ for TOBR and 6.25$37.5 \mu \mathrm{g} / \mathrm{mL}$ for LOTE. Different linearity levels were prepared and injected into the HPLC system keeping the injection volume constant.

\subsubsection{Precision}

Precision of assay was determined by System and Method Precision. Every sample was injected six times. The repeatability of sample application and measurements for peak area were expressed in terms of \%RSD.

\subsubsection{Specificity}

All chromatograms were examined to determine whether compound of interest co-eluted with each other or with any additional excipient peaks. Marketed formulation was analysed to determine the specificity of the optimized method in presence of common excipients.

\subsubsection{Limit of detection and limit of quantification}

Limit of detection (LOD) and limit of quantification (LOQ) were estimated from signal-to-noise ratio. LOD and LOQ were calculated using $3.3 \sigma / \mathrm{s}$ and $10 \sigma / \mathrm{s}$ formulae, respectively. Where, $\sigma$ is the standard deviation of the peak areas and $S$ is the slope of the corresponding calibration curve.

\subsubsection{Robustness}

To evaluate robustness of HPLC method a few parameters were deliberately varied. The parameters included are variation of flow rate and Detection Wavelength.

\subsubsection{Force Degradation studies}

\section{Oxidation}

To $1 \mathrm{ml}$ of stock solution, $1 \mathrm{ml}$ of $20 \%$ hydrogen peroxide $\left(\mathrm{H}_{2} \mathrm{O}_{2}\right)$ was added separately. The solutions were kept for $30 \mathrm{~min}$ at $60^{\circ} \mathrm{c}$. For HPLC study, the resultant solution was diluted to obtain $100 \mu \mathrm{g} / \mathrm{ml}$ and $10 \mu \mathrm{g} / \mathrm{ml}$ solution and $10 \mu \mathrm{l}$ were injected into the system and the chromatograms were recorded to assess the stability of sample.

\section{Acid Degradation Studies}

To $1 \mathrm{ml}$ of stock solution of TOBR and LOTE, $1 \mathrm{ml}$ of $2 \mathrm{~N}$ Hydrochloric acid was added and refluxed for $30 \mathrm{mins}$ at $60^{\circ} \mathrm{c}$.The resultant solution was diluted to obtain $100 \mu \mathrm{g} / \mathrm{ml}$ and $10 \mu \mathrm{g} / \mathrm{ml}$ solution and $10 \mu \mathrm{l}$ solutions were injected into the system and the chromatograms were recorded to assess the stability of sample. 


\section{Alkali Degradation Studies}

To $1 \mathrm{ml}$ of stock solution of TOBR and LOTE, $1 \mathrm{ml}$ of $2 \mathrm{~N}$ sodium hydroxide was added and refluxed for 30mins at 600c. The resultant solution was diluted to obtain $100 \mu \mathrm{g} / \mathrm{ml}$ and $10 \mu \mathrm{g} / \mathrm{ml}$ solution and $10 \mu \mathrm{l}$ were injected into the system and the chromatograms were recorded to assess the stability of sample.

\section{Dry Heat Degradation Studies}

The standard drug solution was placed in oven at $105^{\circ} \mathrm{c}$ for $6 \mathrm{~h}$ to study dry heat degradation. For HPLC study, the resultant solution was diluted to $100 \mu \mathrm{g} / \mathrm{ml}$ and $10 \mu \mathrm{g} / \mathrm{ml}$ solution and $10 \mu \mathrm{l}$ were injected into the system and the chromatograms were recorded to assess the stability of the sample.

\section{Photo Stability studies}

The photochemical stability of the drug was also studied by exposing the $300 \mu \mathrm{g} / \mathrm{ml}, 10 \mu \mathrm{g} / \mathrm{ml}$ and $25 \mu \mathrm{g} / \mathrm{ml}$ solution to UV Light by keeping the beaker in UV Chamber for 7 days or 200 Watt hours $/ \mathrm{m}^{2}$ in photo stability chamber For HPLC study, the resultant solution was diluted to obtain $100 \mu \mathrm{g} / \mathrm{ml}$ and $10 \mu \mathrm{g} / \mathrm{ml}$ solutions and $10 \mu \mathrm{l}$ were injected into the system and the chromatograms were recorded to assess the stability of sample.

\section{Neutral Degradation Studies}

Stress testing under neutral conditions was studied by refluxing the drug in water for $6 \mathrm{~h} \mathrm{r}$ at a temperature of $60^{\circ}$. For HPLC study, the resultant solution was diluted to $100 \mu \mathrm{g} / \mathrm{ml}$ and $10 \mu \mathrm{g} / \mathrm{ml}$ solution and $10 \mu \mathrm{l}$ were injected into the system and the chromatograms were recorded to assess the stability of the sample.

\section{Results and discussion}

During the optimization of HPLC method, two columns symmetry C-18 and C-8 analytical column $(4.6 \times 250 \mathrm{~mm} ; 5 \mu \mathrm{m})$ and $(4.6 \times 150 \mathrm{~mm} ; 5 \mu \mathrm{m})$, organic solvent (acetonitrile), one buffer (phosphate) were tested. Initially Water: Acetonitrile and Phosphate buffer were tried in different ratios. Finally mobile phase consisting of mixture of acetonitrile: Phosphate buffer in ratio $40: 60 \% \mathrm{v} / \mathrm{v}$ was selected as mobile phase to achieve clear separation and sensitivity. Flow rates between 0.8 to $1.2 \mathrm{~mL} / \mathrm{min}$ were studied. A flow rate of $1.0 \mathrm{~mL} / \mathrm{min}$ gave an optimum signal to noise ratio with reasonable separation time using a $\mathrm{C}_{18}$ Zodiac column $(4.6 \times 150 \mathrm{~mm} ; 5 \mu \mathrm{m})$, the retention times for TOBR and LOTE were observed to be 2.442 and 3.269 min respectively. Total run time was less than $7 \mathrm{~min}$. The chromatogram at $243 \mathrm{~nm}$ showed a complete resolution for all peaks (Fig. 3).

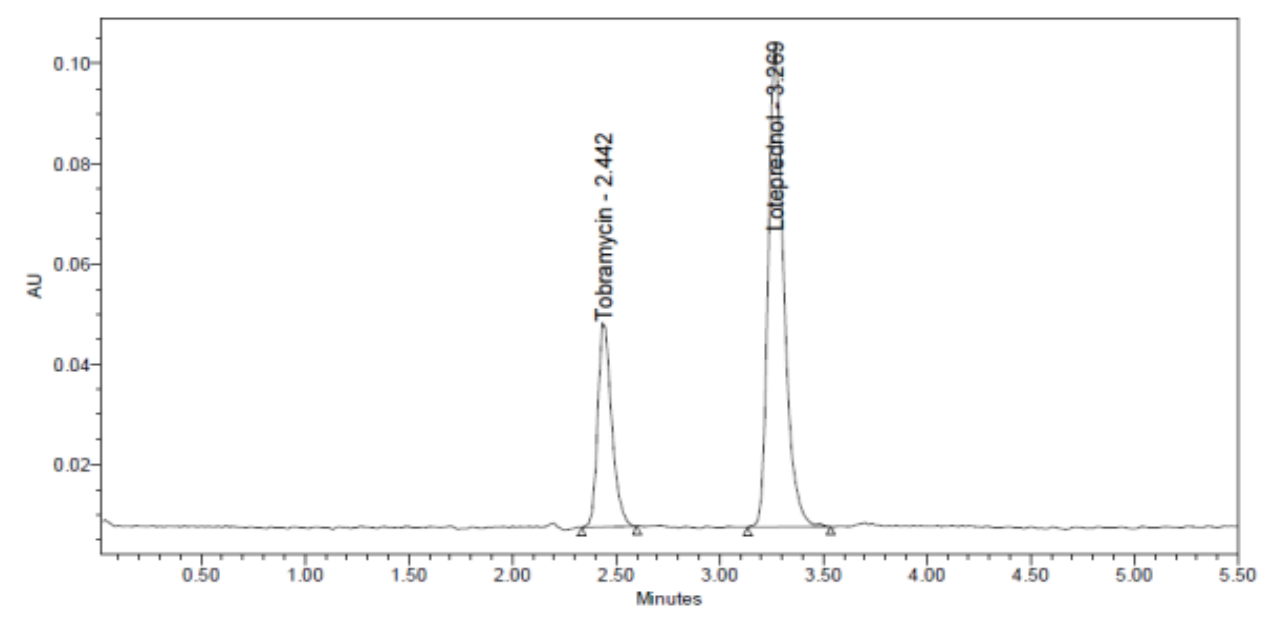

Figure 3 Typical chromatogram of standard for TOBRA and LOTE

Validity of the analytical procedure as well as the resolution between different peaks of interest is ensured by the system suitability tests. All critical parameters tested meet the acceptance criteria on all days. As shown in chromatogram, two analytes are eluted by forming symmetrical peaks. 
Linearity was obtained for TOBR and LOTE in the range of 3.75-22.5 $\mu \mathrm{g} / \mathrm{mL}$ and $6.25-37.5 \mu \mathrm{g} / \mathrm{mL}$. The correlation coefficient $\left(\mathrm{r}^{2}\right)$ was found to be greater than 0.999 in all instances. The results of calibration studies are summarized in Table 1.

Table 1 Linearity table for Tobramycin and Loteprednol

\begin{tabular}{llll}
\hline Tobramycin & & Loteprednol \\
\hline Conc $(\mu \mathrm{g} / \mathrm{mL})$ & Peak area & Conc $(\mu \mathrm{g} / \mathrm{mL})$ & Peak area \\
0 & 0 & 0 & 0 \\
3.75 & 63178 & 6.25 & 128937 \\
7.5 & 120694 & 12.5 & 253509 \\
11.25 & 181816 & 18.75 & 369347 \\
15 & 243565 & 25 & 474971 \\
18.75 & 302855 & 31.25 & 613614 \\
22.5 & 363017 & 37.5 & 732990 \\
\hline
\end{tabular}

The proposed method afforded high recoveries for TOBR and LOTE in dosage form. Results obtained from recovery studies presented in Table 2 indicate that this assay procedure can be used for routine quality control analysis of binary mixture in sample.

Table 2a Accuracy data for Loteprednol

\begin{tabular}{lllll}
\hline \% Level & $\begin{array}{l}\text { Amount Spiked } \\
(\boldsymbol{\mu g} / \mathbf{m L})\end{array}$ & $\begin{array}{l}\text { Amount recovered } \\
(\boldsymbol{\mu g} / \mathbf{m L})\end{array}$ & \% Recovery & $\begin{array}{l}\text { Mean } \\
\text { \%Recovery }\end{array}$ \\
\hline \multirow{2}{*}{$50 \%$} & 7.5 & 7.430 & 99.07 & \\
& 7.5 & 7.466 & 99.55 \\
& 7.5 & 7.496 & 99.95 \\
$100 \%$ & 15 & 14.904 & 99.36 & \\
& 15 & 14.937 & 99.58 & \\
& 15 & 14.881 & 99.20 & \\
$150 \%$ & 22.5 & 22.490 & $99.96 \%$ \\
& 22.5 & 22.352 & 99.34 & \\
\hline
\end{tabular}

Table 2 b Accuracy data for Tobramycin

\begin{tabular}{llcll}
\hline \% Level & $\begin{array}{l}\text { Amount Spiked } \\
(\boldsymbol{\mu g} / \mathbf{m L})\end{array}$ & $\begin{array}{l}\text { Amount recovered } \\
(\boldsymbol{\mu g} / \mathbf{m L})\end{array}$ & \% Recovery & $\begin{array}{l}\text { Mean } \\
\text { \%Recovery }\end{array}$ \\
\hline \multirow{3}{*}{$50 \%$} & 12.5 & 12.476 & 99.81 & \\
& 12.5 & 12.405 & 99.24 & \\
& 12.5 & 12.456 & 99.65 & \\
& 25 & 24.886 & 99.54 & \\
$100 \%$ & 25 & 24.895 & 99.58 & \\
& 25 & 24.795 & 99.18 & \\
& 37.5 & 37.401 & 99.74 & \\
\hline \multirow{2}{*}{$150 \%$} & 37.5 & 37.022 & 99.81 & 99.24 \\
\hline
\end{tabular}


Precision of the analytical method was found to be reliable based on \%RSD $(<2 \%)$ corresponding to peak areas and retention times. As can be seen in Table 3 the \%RSD values were less than 2 for System and Method precision. Hence, the method was found to be precise for these two drugs.

Table 3 Precision data of proposed method

\begin{tabular}{lllll}
\hline S. No. & \multicolumn{2}{l}{ System Precision } & \multicolumn{2}{l}{ method Precision } \\
\cline { 2 - 5 } & Tobramycin* & Loteprednol* $^{*}$ & Tobramycin* & Loteprednol $^{*}$ \\
\hline 1 & 242044 & 473471 & 235044 & 445390 \\
2 & 239658 & 474567 & 235658 & 444567 \\
3 & 240636 & 478549 & 235636 & 438549 \\
4 & 239711 & 478981 & 234711 & 442551 \\
5 & 240134 & 472187 & 235330 & 440819 \\
6 & 241725 & 476737 & 232686 & 446737 \\
Mean & 240651 & 475749 & 234844 & 443102 \\
Std. Dev. & 1022.8 & 2776.2 & 1117.2 & 3060.7 \\
\hline \%RSD & $\mathbf{0 . 4}$ & $\mathbf{0 . 6}$ & $\mathbf{0 . 5}$ & $\mathbf{0 . 7}$ \\
\hline
\end{tabular}

The chromatograms were checked for appearance of any extra peaks under optimized conditions, showing no interference from common excipients and impurities. Also the peak areas were compared with standard and percentage purity calculated was found to be within limits. LOD and LOQ were found to be $0.07 \mu \mathrm{g} / \mathrm{mL}$ and $0.21 \mu \mathrm{g} / \mathrm{mL}$ for TOBR, $0.15 \mu \mathrm{g} / \mathrm{mL}$ and $0.45 \mu \mathrm{g} / \mathrm{mL}$ for LOTE. In all deliberately varied conditions, the \%RSD for replicate injections of TOBR and LOTE were found to be within the acceptable limit. The tailing factors for two peaks were found to be less than 1.5 and the results are shown in Table 4.

Table 4 Robustness for flow rate variation of TOBRA and LOTE.

\begin{tabular}{llcc}
\hline S.NO & Robustness condition & Tobramycin Area \%RSD & Loteprednol Area \%RSD \\
\hline 1 & Flow rate- 0.9 & 0.9 & 0.7 \\
2 & Flow rate-1.1 & 0.9 & 0.4 \\
3 & Mobile Phase $(65: 35)$ & 0.8 & 0.3 \\
4 & Mobile Phase $(55: 45)$ & 0.7 & 0.6 \\
5 & Temperature- $25^{\circ} \mathrm{C}$ & 0.8 & 0.5 \\
6 & Temperature- $35^{\circ} \mathrm{C}$ & 0.6 & 0.7 \\
\hline
\end{tabular}

The validated method was used in analysis of marketed tablet dosage form. The results for the drugs assay showed good agreement with label claims and the results are shown in Table 5. Degradation studies results were shown in Table 6 and 7.

Table 5 Analysis of marketed formulation by proposed method

\begin{tabular}{lllll}
\hline Brand Name & Drug & Labelled claim & Amount found* & \% Assay* \\
\hline LACNE & Tobramycin & $0.3 \%$ & $9.98 \mathrm{mg}$ & 99.89 \\
& Loteprednol & $0.5 \%$ & $4.99 \mathrm{mg}$ & 99.89 \\
\hline
\end{tabular}


Table 6 Degradation Data of Tobramycin

\begin{tabular}{llll}
\hline S. No. & Degradation Condition & \% Drug found & \% Drug Degraded \\
\hline 1 & Acid & 94.46 & 5.54 \\
2 & Alkali & 95.52 & 4.48 \\
3 & Oxidation & 96.34 & 3.66 \\
4 & Thermal & 96.85 & 3.15 \\
5 & UV & 98.77 & 1.23 \\
6 & Neutral & 98.77 & 1.23 \\
\hline
\end{tabular}

Table 7 Degradation Data of Loteprednol

\begin{tabular}{llll}
\hline S. No. & Degradation Condition & \% Drug found & \% Drug Degraded \\
\hline 1 & Acid & 94.08 & 5.92 \\
2 & Alkali & 96.13 & 3.87 \\
3 & Oxidation & 96.92 & 3.08 \\
4 & Thermal & 97.82 & 2.18 \\
5 & UV & 98.33 & 1.67 \\
6 & Neutral & 99.23 & 0.77 \\
\hline
\end{tabular}

\section{Conclusion}

The developed stability indicating RP-HPLC method is simple, specific, accurate and precise for the simultaneous determination of TOBR and LOTE in combined tablet dosage form. The developed method provides good resolution between TOBRA and LOTE. It was successfully validated in terms of system suitability, linearity, precision, accuracy, specificity, LOD, LOQ and robustness in accordance with ICH guidelines. Thus the described method is suitable for routine analysis and quality control of pharmaceutical preparations containing these drugs either as such or in combination.

\section{Compliance with ethical standards}

\section{Acknowledgments}

The authors are thankful to the Management of Hindu college of pharmacy, Guntur for providing necessary facilities to carryout the present research work.

\section{Disclosure of conflict of interest}

No conflict of interest.

\section{References}

[1] https://www.drugbank.ca/drugs/DB00873

[2] https://www.drugbank.ca/drugs/DB00684

[3] https://www.drugs.com/sfx/Tobramycin-side-effects.html

[4] Qi X and Longhua Y. (2012). Determination of Edetate Disodium Dihydrate in Loteprednol and Tobramycin Ophthalmic Suspension by RP-HPLC [J]. China Pharmaceuticals, 1.

[5] Saxena V and Singh A. (2013). Development and validation of HPLC method for the simultaneous estimation of loteprednol and gatifloxacin. International Journal of Science and Research, 2, 252-5. 
[6] Valentini F, Buldini PL, Landi E, Tampieri A and Tonelli D. (2008). HPLC determination of tobramycin in a simulated body fluid. Microchemical Journal, 90(2), 113-7.

[7] Comstock TL and Holland EJ. (2010). Loteprednol and tobramycin in combination: a review of their impact on current treatment regimens. Expert opinion on pharmacotherapy, 11(5), 843-52.

[8] Mashat M, Chrystyn H, Clark BJ and Assi KH. (2008). Development and validation of HPLC method for the determination of tobramycin in urine samples post-inhalation using pre-column derivatisation with fluorescein isothiocyanate. Journal of Chromatography B, 869(1-2), 59-66.

[9] Patel AB and Patel DB. (2013). Development and validation of RP-HPLC method for simultaneous estimation of gatifloxacin and loteprednol etabonate in pharmaceutical dosage form. Asian Journal of Research in Chemistry, 6(4), 393-7.

[10] Dagneaux PK and Elhorst JK. (1981). HPLC-estimation of tobramycin in serum. Pharmaceutisch weekblad, 3(1), 582-6.

[11] Russ H, McCleary D, Katimy R, Montana JL, Miller RB, Krishnamoorthy R and Davis CW. (1998). Development and validation of a stability-indicating HPLC method for the determination of tobramycin and its related substances in an ophthalmic suspension. Journal of liquid chromatography and related technologies, 21(14), 2165-81.

[12] Pfeifer C, Fassauer G, Gerecke H, Jira T, Remane Y, Frontini R, Byrne J and Reinhardt R. (2015). Purity determination of amphotericin B, colistin sulfate and tobramycin sulfate in a hydrophilic suspension by HPLC. Journal of Chromatography B, 990, 7-14.

\section{How to cite this article}

Nagaraju P, Kiran Kumar P, Aparna G and Suneetha M. (2020). Novel stability indicating RP-HPLC method for the simultaneous estimation of tobramycin and loteprednol in pharmaceutical dosage forms. GSC Biological and Pharmaceutical Sciences, 10(1), 73-80. 